\title{
Resource location and structural properties of the nestbox as determinants of nest-site selection in the golden hamster
}

\author{
EDUARDO B. OTTONI and CÉSAR ADES \\ University of São Paulo, São Paulo, Brazil
}

\begin{abstract}
Nest-site selection, an ecologically relevant behavior, was studied in the golden hamster in a model environment where the animals could choose between nestboxes differing in distance from resource or in structural features (size and illumination). Experiment 1 showed that hamsters can decrease foraging costs by setting their nests in the nestbox nearest to the food and/or nestmaterial sources, and that hoarding costs, as distinct from simple procurement costs, are taken into account in the choice process. Preferences for darker and larger nestboxes were obtained in Experiment 2. Experiment 3 revealed an internally coherent hierarchical pattern in preferences, with illumination being more important than size and resource distance, and size more important than resource distance. The results suggest that nest-site selection and foraging behaviors are parts of an integrated causal system.
\end{abstract}

Nest-site selection by rodents is a complex process involving an evaluation of the structural features of potential nests or nest sites (size, illumination, depth, consistency of soil, etc.), as well as of spatial relationships between such sites and environmental resources, such as food, water, and protective covers.

A great amount of information about nest-site and habitat selection comes from field studies in which the distribution of animals or burrows is assessed relative to relevant environmental features, such as temperature, humidity, kinds of vegetative cover, presence of competing species, and so on (Barry \& Francq, 1980; Christian, 1980; Dueser \& Hallett, 1980; Lacher \& Alho, 1989). In their study of the distribution of Norway rats' burrows in a landfill, Lore and Flannelly (1978) showed that the animals exhibited a strong preference for digging their burrows on sloping ground, in soil that offered little resistance to excavation, and at a relatively short distance from food and water sources.

Such studies, important as they are in revealing the relevant ecological conditions for the establishment of burrows, should be complemented by experimental studies with the aim of determining exactly what proximate factors are at work. Despite its relevance as a species-specific behavioral pattern, nest-site selection has not been fre-

Preparation of this article was supported in part by FINEP, FAPESP, and CNPq. We would like to thank the reviewers for their helpful comments on this work. The authors' mailing address is Departamento de Psicologia Experimental, Instituto de Psicologia, Universidade de São Paulo, Cidade Universitária, Av. Prof. Mello Moraes, 1721, CEP 05508, São Paulo, SP, Brazil. quently taken as an object for experimental analysis in behavioral laboratories. Attention has mostly been given to foraging behavior, and many studies on search, procurement, handling, and storage of food, inspired by optimal foraging theory, have been performed using laboratory analogues of natural conditions (Collier, 1983; Shettleworth, 1988). It is worth noting that, in the case of burrowing rodents that use their nests or temporary shelters as reference sites during the exploitation of resources (centralplace foragers), choice of nest site or protective cover is an essential part of the foraging process.

Experiments by Buhot $(1986,1987,1989$; BuhotAverseng, 1981), which are among the few recently published on the topic, show that white mice, when tested in groups, tended to use the size of the nestbox as their main choice criterion, and that shape can also be taken into account: rectangular nestboxes were chosen from a set that included rectangular, square, and circular nestboxes. Buhot's $(1986,1987)$ results suggest that the influence of structural features depends on the type of activity mice are engaged in: criteria for exploratory behavior differ from those used during nest establishment.

The goal of the present study was to examine, using a laboratory model, the influence of both structural (size and illumination of the nestbox) and positional (distance of the nestbox from food and/or nest-material resources) variables on nest-site selection by golden hamsters. We first studied, in Experiments 1 and 2, choice between alternatives taken from the same stimulus dimension (distance from resources, nestbox size, and illumination). In Experiment 3, to reveal any hierarchy of preferences among dimensions, we performed tests in which size, illumination, and distance to resource were pitted against each other. 


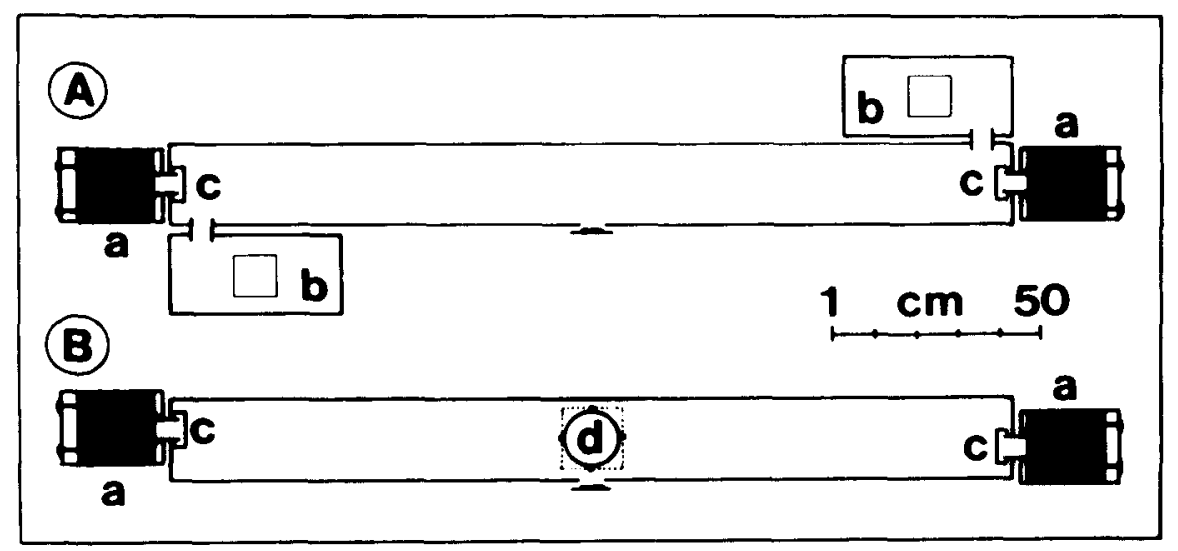

Figure 1. Overhead diagrams of the experimental runway: (A) Configuration A; (B) Configuration B; (a) nestboxes; (b) side "resource" compartments; (c) nestbox entrances; (d) vertical paper dispenser.

\section{GENERAL METHOD}

\section{Subjects}

Our subjects were 230 golden hamsters of a single strain from the colony of the Department of Experimental Psychology at the University of São Paulo. Litters were weaned when about 30 days old; the hamsters were transferred, at approximately $\mathbf{5 0}$ days of age, to individual steel cages, where they had free access to food, water, and nest material. They remained in their cages until experimental testing. The animals were tested between 2 and 6 months of age.

\section{Apparatus}

The apparatus was a Plexiglas runway ( $2 \mathrm{~m}$ long; Figure 1), at the extremities of which were connected the potential nestboxes, their entrances being PVC cylinders $(6 \mathrm{~m}$ long and $6 \mathrm{~cm}$ in diameter). Nestboxes were either 2-liter glass bottles or Plexiglas boxes (Experiments 2B, 3B, and 3C), which could be easily washed and deodorized between trials, obscured by black plastic covers (bottles) or paint (boxes) unless otherwise indicated.

Food and paper strips could be offered either at the center or near one of the extremities of the runway. In Experiments 1A (Test 1) and $1 \mathrm{D}$, Plexiglas side compartments were used as resource sites (Figure 1A). They measured $45 \times 20 \times 20 \mathrm{~cm}$ and were connected to the runway by means of a tube $(6 \mathrm{~cm}$ in diameter), the entrance of which was situated $10 \mathrm{~cm}$ from the nearest nestbox entrance; in all other conditions, food and/or paper strips were available in the runway proper. The animals could then obtain strips from a vertical paper dispenser (10 cm above floor level; Figure 1B). To avoid preferences that could be due to some undetected variable associated with one of the sides of the apparatus (left/right), in each of the experiments, resources or differently structured nestboxes were put half of the time at the left side and half of the time at the right side.

Movements of the animals at the entrance of each nestbox were recorded through pedal-operated microswitches (size of pedal = $5 \times 2 \mathrm{~cm}$ ) located just under the nestbox entrance, $3 \mathrm{~cm}$ from the floor. These movement data were particularly relevant for other topics (Ottoni \& Ades, 1988), not reported in the present paper. Illumination of the runway was kept constant throughout each session at approximately $100 \mathrm{~lx}$ at floor level.

\section{Procedure}

Each hamster was subjected to a single 23 -h test session. At the beginning of the session, which occurred at 4:00 p.m., each animal was placed in the center of the runway. Behavioral categories displayed during the first $\mathbf{3 0} \mathrm{min}$ of the session (exploration, foraging, nest building, etc.) were observed, and the pedal activity scores recorded. At the end of the session, the location of the subject and of its nest (where it was usually found asleep), the pedal activity scores for each nestbox and the distribution of paper strips, food, and fecal boluses were registered. Location of the animal and of its nest were usually sufficient as criteria of nest-site choice. In a few cases, when a subject was found awake and moving along the runway, the location of nests or food/paper hoards and the activity scores were taken as indications of the chosen nest site.

We tested the animals of both sexes and pooled their data within each experimental condition, sex not being an experimental variable in this study (both sexes build nests).

Experimental conditions and statistically significant results are displayed in Table 1. Analysis of choice data was made with a twotailed binomial test; hoarding comparisons in Experiment $1 \mathrm{D}$ employed Student's $t$ test.

Table 1

Variables and Statistically Significant Results $(p<.05)$

\begin{tabular}{|c|c|c|}
\hline $\begin{array}{c}\text { Ex- } \\
\text { periment }\end{array}$ & Variables & Results \\
\hline $1 \mathrm{~A}$ & $\begin{array}{l}\text { Distance from paper/food } \\
\text { Test 1. Paper in side compartment } \\
\text { Test 2. Paper in dispenser }\end{array}$ & $\begin{array}{l}\text { Near }>\text { Far } \\
\text { Near }>\text { Far }\end{array}$ \\
\hline 1B & Distance from paper & Near $>$ Far \\
\hline $1 \mathrm{C}$ & $\begin{array}{l}\text { Distance from food } \\
\text { Test 1. Food powder }(30 \mathrm{~g}) \\
\text { Test 2. Pellets }(300 \mathrm{~g})\end{array}$ & Near $>$ Far \\
\hline $1 \mathrm{D}$ & $\begin{array}{l}\text { Paper } \times \text { food } \\
\text { Test } 1 . \text { Food pellets } \\
\text { Test } 2 . \text { Food powder }\end{array}$ & - \\
\hline IE & $\begin{array}{l}\text { Food pellets } \times \text { food powder } \\
\text { Test } 1.50 \mathrm{~g} \text { available } \\
\text { Test } 2.300 \mathrm{~g} \text { available }\end{array}$ & - \\
\hline $\begin{array}{l}2 \mathrm{~A} \\
2 \mathrm{~B}\end{array}$ & $\begin{array}{l}\text { Dark } \times \text { clear nestbox } \\
\text { Small } \times \text { large nestbox } \\
\text { Test } 1.30 \mathrm{~g} \text { of paper available } \\
\text { Test } 2.1 \text { paper strip available }\end{array}$ & $\begin{array}{l}\text { Dark }>\text { Clear } \\
\text { Large }>\text { Small } \\
\text { Large }>\text { Small }\end{array}$ \\
\hline $\begin{array}{l}3 \mathrm{~A} \\
3 \mathrm{~B} \\
3 \mathrm{C}\end{array}$ & $\begin{array}{l}\text { Illumination } \times \text { distance from paper } \\
\text { Illumination } \times \text { nestbox size } \\
\text { Nestbox size } \times \text { distance from paper }\end{array}$ & $\begin{array}{l}\text { Dark }>\text { Near } \\
\text { Dark }>\text { Large } \\
\text { Large }>\text { Near }\end{array}$ \\
\hline
\end{tabular}




\section{EXPERIMENT 1}

Experiment 1 was concerned with the effects of distance between resources and potential nestboxes. Studies of foraging behavior suggest that animals attempt to minimize the amount of time and energy expended in obtaining food resources (Partridge, 1978). If nest-site selection is controlled by such an energy-saving principle, hamsters should choose the nestbox closer to the resource site. One further question addressed was the relative power of food or nest material to induce choice of the nearest nestbox.

\section{Experiment 1A: Distance From Food and Paper Resource}

This experiment was done in two replications. In the first one, the animals ( $n=20,6$ females $/ 4$ males) had to choose between a nestbox near a side compartment with $30 \mathrm{~g}$ of paper strips and $30 \mathrm{~g}$ of food pellets and another nestbox near a symmetrical but empty side compartment. In the second test ( $n=10,8$ females $/ 2$ males), conditions were the same, except that paper was offered in the paper dispenser.

Of the 20 subjects in the first test, 3 made their nest in the side compartment where food and paper strips were offered. Of the 17 remaining subjects, 16 chose the nestbox near the full side compartment, a statistically significant result (binomial test, $n=17, p<.001$ ). The second test had similar results. One of the subjects built its nest in the runway. Of the remaining 9 subjects, 8 chose the nestbox near the side compartment containing food and paper (binomial test, $n=9, p<.05$ ).

\section{Experiment 1B: Distance From Paper Resource}

Choice was between a nestbox near the paper dispenser and a nestbox far from it ( $n=10,5$ females/5 males).

All 10 subjects built their nests in the nestbox near the paper dispenser, a highly significant result (binomial test, $n=10, p<.002$ ).

\section{Experiment 1C: Distance From Food Resource}

In the first of two tests ( $n=10,5$ females $/ 5$ males), choice was between nestboxes that were near or far from $30 \mathrm{~g}$ of food powder; in the second one ( $n=10,9$ females/ 1 male), between nestboxes that were near or far from $300 \mathrm{~g}$ of pellets.

No significant effects were observed in the first test, when food was offered as powder in one side of the apparatus: four nests were built in the nestbox near the food resource, six nests in the distant one (binomial test, $n=$ $10, p>.05$ ). Food in pellets was, in contrast, successful in influencing choices: in the second test, 9 out of 10 nests were made in the near nestbox (binomial test, $n=$ $10, p<.05$ ).

\section{Experiment 1D: Food Resource Versus Nest-Material Resource}

In the first test ( $n=20,12$ females $/ 8$ males), food pellets $(30 \mathrm{~g})$ were put in one of the side compartments and paper strips in the other. In the second test $(n=20$, 11 females $/ 9$ males), conditions were the same except that the food was offered in powder.

Our data did not indicate any significant tendency favoring either the paper or the food side of the apparatus. In the first test, 9 animals made nests in the nestbox near the food resource and 9 in the nestbox near the paper resource. The remaining 2 slept in the side compartment loaded with paper. The same results were obtained in the second test, with 12 nests near the paper resource, 6 near the food resource (binomial test, $n=18, p>.05$ ), and 2 nests in the paper source.

In the first test, the animals situated near the paper source hoarded a mean of $17.4 \mathrm{~g}$ of paper strips, whereas those far from it hoarded $3.2 \mathrm{~g}[t(16)=5.09, p<.001]$. The hamsters with their nests near the food source hoarded a mean of $18.1 \mathrm{~g}$ of food, whereas those far from it hoarded a mean of $5.3 \mathrm{~g}[t(16)=3.174, p<.01]$, though food consumption was the same in both conditions. In the second test, there was again a significant difference between mean amounts of paper strips hoarded in near and far nestboxes [25.9 and $8.0 \mathrm{~g}$, respectively; $t(16)=4.480, p<.001]$; food hoarding, here, was practically null (powder food), but its consumption was, again, the same for the animals with nests near or far from the food source.

\section{Experiment 1E: Pellets Versus Food Powder}

In the first of two tests ( $n=10,2$ females $/ 8$ males), there were $50 \mathrm{~g}$ of pellets on the floor near one of the nestboxes and $50 \mathrm{~g}$ of food powder in a dish near the other one; in the second test ( $n=10,4$ females $/ 6$ males), there were $300 \mathrm{~g}$ of pellets at one site and $300 \mathrm{~g}$ of food powder at the other site.

In both tests, most of the animals -8 out of 10 -made their nests in the nestbox near the pellets, a result that may express some preference, although significance was not reached (binomial test, $n=10, p=.11$ ).

Direct observation of the hamsters, during the first $30 \mathrm{~min}$ of the session, in all these experiments, showed that they explored the apparatus extensively, spending a relatively long time exploring the food and/or paper sources. A few hamsters, nevertheless, took cover for some time in the first nestbox found, maybe as a consequence of escape tendencies elicited by entry into a novel environment.

\section{Discussion}

Results of Experiments 1A, 1B, and 1C demonstrate that hamsters use the distance between potential nest site and resource site as a criterion of nestbox choice. Distance acted as a controlling factor in the case of both single-resource patches (pellets or paper strips; Experiments 1B and 1C) and double-resource patches (pellets and paper strips; Experiment 1A), but not in the case of powdered food (Experiment 1C).

Previous research in our laboratory (Guerra \& Ades, 1982,1983 ) indicates that hamsters are quite sensitive to cost conditions-be it in terms of time spent or distance 
traveled-when foraging for nest material. Results of that research indicates that (1) the overall amount of strips gathered decreases as the distance between nestbox and resource site increases (the amount carried in each foraging trip, however, increases with distance), (2) animals consistently choose the nearest resource site for gathering strips, but continue to visit the more distance ones, and (3) experimentally imposed increases in traveling time have the same effects on foraging strategies as increases in distance. Similar results have been obtained with the rat (Collier \& Rovee-Collier, 1980; Killeen, Smith, \& Hanson, 1981; Smith, Maybee, \& Maybee, 1979).

The present results show that cost reduction can also be obtained through choice of the nearest nestbox or central place and are in accordance with Lore and Flannelly's (1978) observation that rats, in a natural environment, tend to place their burrows a short distance from water and food resources. The occurrence, in Experiments 1A (Test 1) and 1D (Tests 1 and 2), of the peculiar behavior of building nests in the source side compartment itself can be interpreted as a quite efficient strategy for reducing costs.

Travel distance economy is cumulative and has more of an impact as the frequency of trips increases. This is why we should expect it to be a more potent influence in the case of hoarding, which implies more travels, than in the case of procuring and eating food at the resource site. Results of Experiment IC seem to be in line with this expectation: a patch with food pellets (an opportunity for hoarding) induced hamsters to build their nests in nearby boxes; this did not occur in the case of a patch with powdered food. When evaluating the material present in a patch, be it food or some other kind of material, hamsters seem to take into account its quality of being transportable or hoardable. Hoarding cost has to be distinguished from simple procurement cost.

The procurement cost, even if lower than the hoarding cost, did not cause a near-nestbox choice when powdered food was available (Experiment $1 \mathrm{C}$ ). A possible explanation is that animals at a farther nestbox can decrease response cost through an "eat more on each travel and travel fewer times" strategy. The alternative of choosing the near nestbox would not be distinctly better than choosing the far nestbox. It would be interesting, in further experiments, to verify if meal duration is really longer when travel is longer, and if such an increase is sufficient to compensate for the distance-induced reduction in number of trips.

\section{EXPERIMENT 2}

Experiment 2 was concerned with the influence of structural variables (nestboxes' illumination and size) on nestbox choice in the hamster.

\section{Experiment 2A: Illumination of Nestbox}

The animals ( $n=20,12$ females $/ 8$ males) could choose between an illuminated nestbox and a dark one. Nestboxes were 2 -liter bottles-the dark one covered with a black plastic sheet, and the illuminated one without it. The paper dispenser, at the center of the runway, contained $30 \mathrm{~g}$ of paper strips; $30 \mathrm{~g}$ of food pellets were scattered nearby.

The proportion of choices of the dark nestbox significantly differed from chance. All 20 subjects chose it for nest building (binomial test, $n=20, p<.001$ ). Paper and food were never stored in the illuminated nestbox.

\section{Experiment 2B: Size of Nestbox}

The subjects in the first test $(n=20,12$ females $/ 8$ males) had to choose between two boxes differing in size. Both were made of black-painted Plexiglas. The smaller box had an $18 \times 18 \mathrm{~cm}$ base, and the larger one had a $27 \times 27 \mathrm{~cm}$ base (both $10 \mathrm{~cm}$ high). In the first test, $30 \mathrm{~g}$ of pellets and $30 \mathrm{~g}$ of paper strips were available at the center of the runway. In the second test $(n=10$, all males), the same amount of food was offered, along with a single paper strip. Our purpose was to verify whether the availability of nest material could alter the hamsters' preference for differently sized nestboxes. Results from our laboratory (Cromberg, 1988) suggest that hamsters build larger burrows when they have larger numbers of pellets to hoard. It seemed plausible to expect the hamsters to choose nestboxes according to the number of paper strips available.

In both tests, a significant proportion of the animals chose the larger nestbox. In the first test $(30 \mathrm{~g}$ of strips available), 17 of 20 subjects built nests in the large nestbox, 2 subjects chose the smaller one, and 1 subject built its nest in the runway under the paper dispenser (binomial test, $n=19, p<.01$ ). The animals had a relatively high level of exploration of the small nestbox, but only 4 (including the 2 subjects that used it as a nest site) stored any amount of paper in it. In the second test (only one strip available), 9 of 10 subjects built their nests in the large nestbox (binomial test, $n=10, p<.05$ ).

\section{Discussion}

Illumination. Experiment $2 \mathrm{~A}$ shows that hamsters have a strong preference for dark (as opposed to illuminated) nestboxes. This result confirms previous findings in the literature about nest-site selection by rodents and agrees with what one would intuitively expect. In her study of nestbox choice in mice, for instance, Buhot-Averseng (1981) found that the ranking of preferences was directly related to the opacity of the boxes.

Rodents not only prefer dark and closed places as nest sites, but frequently use them as temporary shelters while foraging. Nicolaidis, Danguir, and Mathe (1978) reported significant changes in rats' behavior when they were provided with a dark enclosure that acted as a safe place. Several species of small rodents change their pattern of exploratory behavior in an unfamiliar environment if they are allowed to enter a small, dark box. This is the case with Mus musculus and Acomys cahirinus (Birke, D'Udine, \& Albonetti, 1985), as well as with Calomys callosus (Alberts, 1989) and with Rattus norvegicus and Rattus rattus (Barnett, 1975). 
We may speculate that, in natural environments, illuminated sites are associated with higher predation risks, and they generate an avoidance tendency. Conversely, dark, covered places may represent relatively secure sites and may come to function as shelters or home bases. The aversive character of strong illumination was noted by Charlton (1984) as a possible determinant of hoarding in hamsters. An illuminated box may simply lack an essential feature of a protected site.

Size. The preference for the larger nestbox confirms unpublished results from our laboratory (Ottoni, 1987), showing that hamsters will use size as a criterion of choice when tested in an apparatus with four different nestboxes available. The boxes, like those used in the present study, were made of opaque Plexiglas and had 100, 200, 400, and $800 \mathrm{~cm}^{2}$ of basal area (all of them $10 \mathrm{~cm}$ high). There was a direct proportional relationship between size of nestbox and the value of a choice index, which combined different criteria of nestbox occupation (presence of the animal, amount of food hoarded, amount of paper collected, and presence of urine or fecal boluses).

Hamsters make substantial burrows when appropriate substrate conditions are available, with large chambers where they stock hoard (Cromberg, 1988; Ropartz, 1962). The choice of the largest nestbox, in the present study, may be understood as a way the subjects had to obtain the roomiest chamber, without having to dig it. This criterion of choice may constitute part of a time- and effortsaving strategy.

Our results are at variance with some of Buhot's. She found, in individual mice, a preference for the smaller, rectangular nestboxes, despite a more intense exploration of larger ones (e.g., Buhot-Averseng, 1981). When tested socially, mice were observed to take size into account (Buhot, 1986), and reject the smallest of a series of boxes, maintaining, however, a linear ranking of preference for all the others inversely proportional to increasing size (Buhot, 1987).

One possible account of the discrepancy is motivational. In Buhot's experiments, mouse behavior might have been controlled more by relative safety than by relative storage capacity. In our study, the animals had plenty of time to explore and to get familiar with all aspects of the runway and nestboxes, and they normally made a great number of hoarding trips, once they established themselves in one of the nestboxes. Therefore, stress or escape tendencies may have contributed less to their performance. The nestboxes appear to have functioned as burrows, not as mere shelters, and were probably selected on the basis of structural properties relevant to permanent nests.

In a more recent paper, Buhot (1989) reported an experiment in which roofed nestboxes were offered instead of the open ones previously used; in this case, mice's preferences correlated positively with box size, in agreement with our results.

The fact that lesser availability of nest material did not change the hamsters' preference for the larger nestbox suggests that this preference was controlled by stimulus properties of the nestbox itself.

\section{EXPERIMENT 3}

The purpose of Experiment 3 was to obtain information about a possible hierarchy of influence of structural and spatial variables in nest-site selection. Variables (distance from nest-material source, illumination, and size of nestbox) were those manipulated in Experiments 1 and 2 .

\section{Experiment 3A: Illumination Versus Distance From Resource}

A dark nestbox (a 2-liter glass bottle covered with a sheet of black plastic) $190 \mathrm{~cm}$ from the paper dispenser and an illuminated one (a transparent 2-liter glass bottle) $10 \mathrm{~cm}$ from the paper dispenser were the available alternatives ( $n=20,5$ females/15 males).

A significant proportion of the hamsters chose the dark nestbox, far from the dispenser: 19 of 20 subjects occupied this nestbox (binomial test, $n=20, p<.01$ ); 18 of these 19 subjects built their nests in it (1 subject failed to collect strips during the session). Of these 18 animals, only 3 brought some strips of paper into the other nestbox, near the dispenser.

\section{Experiment 3B: Illumination Versus Size}

The animals ( $n=20,15$ females $/ 5$ males) chose between a small and dark box $(18 \times 18 \times 10 \mathrm{~cm}$ high Plexiglas box with walls painted black) and a large and illuminated box $(27 \times 27 \times 10 \mathrm{~cm}$ high Plexiglas box $)$.

Illumination prevailed over size. There were 17 choices of the dark, small nestbox, and only two choices of the transparent, large one (binomial test, $n=19, p<.001$ ). One nest was built in the runway. Only 1 of the hamsters that chose the dark nestbox left some strips of paper in the other nestbox, and only 2 of them hoarded any amount of food in it. On the other hand, choice was ambiguous for 1 of the 2 animals that nested in the transparent nestbox. This animal transported only $1.0 \mathrm{~g}$ of paper to it, whereas it stored $6.5 \mathrm{~g}$ of paper in the dark nestbox.

\section{Experiment 3C: Size Versus Distance \\ From Resource}

The animals ( $n=20,11$ females/9 males) chose between dark nestboxes, one of which was large $(27 \times 27 \times 10 \mathrm{~cm}$ high Plexiglas box $)$ and far $(190 \mathrm{~cm})$ from the paper dispenser and the other of which was small $(18 \times 18 \times 10 \mathrm{~cm}$ high Plexiglas box) and near $(10 \mathrm{~cm})$ the paper dispenser.

Size prevailed over distance from resource. There were 18 choices of the large nestbox, located far from the dispenser, and only 2 choices of the small one (binomial test, $n=20, p<.001$ ). Among the hamsters that chose the large nestbox, 5 left some strips of paper in the other nestbox; among those that chose the small nestbox, 1 left some strips in the large one and the other hamster stored food in it. 


\section{Discussion}

These experiments constitute, to our knowledge, the first direct examination of the relative influence of structural (illumination and size of nestbox) and positional (distance from source) variables on nest-site selection. Two interesting features of the results are the clear-cut nature and the transitivity of preferences: illumination $>$ size $>$ distance from resource (size prevailed over distance from resource, and illumination prevailed over both size and distance).

Such ranking suggests, in the first place, that nest-site selection should not be taken as a simple and automatic product of a distance-from-resource minimizing strategy. In certain circumstances, such as those that prevailed in our study, the intrinsic features of a potential nest or nest site will strongly affect behavior to the point of nullifying the influence of spatial factors. In natural conditions, nest-site selection probably represents a tradeoff between foraging efficiency (placing the burrow near the resource) and the need to construct the burrow in a convenient site, from the standpoint of soil and terrain.

Some indication of the preponderance of darkness and/or enclosure factors over internal size can be found in Buhot (1989), although that author did not perform tests pitting roofed against roofless sites (see also opacity preferences in Buhot-Averseng, 1981).

Structural variables may not always have more influence than positional ones. Had the distance between the farthest nestbox and the paper dispenser been larger (meaning an increase in foraging cost), decisions about where to build the nest could have been different, with a bias toward nearness to resources.

\section{GENERAL DISCUSSION}

Optimal foraging principles, which have served as a guide for numerous studies in both experimental psychology and behavioral ecology (Shettleworth, 1988), make us expect that animals will maximize the energy intake per unit time spent foraging. Results of Experiment 1A, 1B, and $1 \mathrm{C}$ show that optimization can be obtained, in central-place foragers such as hamsters, through decision rules about where to place the nest. Faced with a given spatial distribution of patches, a central-place forager with an already-built nest can either adopt a strategy that permits the best possible utilization of available resources without changing the location of its nest or move the nest and, thus, decrease traveling costs. Switching from the former to the latter strategy obviously depends on the cost of leaving an already-established nest and finding a suitable site for building another one. The distance between the nest and available resources is likely to be involved in such switching: the more distant the resources, the more probable will be the use of a moving strategy, if adequate nest sites are available.

Is the strategy of choosing the nestbox nearest to the resources actually an efficient one? One possible criterion of efficiency could be the total amount of paper strips or food pellets gathered during the whole session, taken as a time unit. In Experiment 1D (food vs. paper), there were enough animals choosing either the near or far nestboxes to allow the comparison between overall gains: the animals situated near the paper source hoarded more paper strips than did those far from the source, whereas the hamsters with their nests near the food source (Test 1) hoarded more pellets than did those far from it (in Test 2, the powdered food prevented hoarding), though food consumption was the same in both conditions. Thus, from the viewpoint of foraging, the nearest-to-resources strategy of choosing the nest site is advantageous.

Structural features of the nest, such as its illumination or size (Experiments 2 and 3), are also important aspects taken into account by the animals. There are probably benefits (from the point of view of defense against predators) in choosing a dark enclosure to build the nest. The defense objective may conflict with the foraging objective, and there may be intra- or interspecific competition for preferred sites (Partridge, 1978). Such logic suggests that, in the field, burrows may be found at a range of distances from resource sites, some of them less than optimal from the point of view of foraging efficiency.

Early exploration of the apparatus seems to play an important role in the choice process. The animals showed evidence of visiting virtually every part of the apparatus and-by moving around, sniffing, and rearing-could acquire knowledge of relevant sites (nests and sources) and of the distance between them. Poucet, Chapuis, Durup, and Thinus-Blanc's (1986) study showed how apt hamsters are at forming, through exploratory behavior, an internal representation of spatial features of the environment.

Distances between sites are probably not the only environmental features encoded. Animals assess hoarding costs of food (Experiments $1 C$ and $1 E$ ), probably by performing transport trips between the resource site and the nests, and acquire information about the structural features of each nestbox visited. Choice seems to involve a comparison between features of alternative nest sites, not a "find-and-stay" strategy, elicited by local features of any nest site (Experiment 3).

Results such as those reported here should not be taken as necessarily valid from the standpoint of the behavior of hamsters in their natural environment: constraints of a laboratory environment can affect naturally occurring activities. It is important that parallel studies--in the field and in the laboratory-be conducted on the same foraging problem, in order to have an adequate understanding of the processes involved. In spite of this, we think that our approach draws attention to an essential and seldomstudied behavior, the selection of a site for nest building, and provides a simple experimental strategy for the analysis of some of its outstanding features.

\section{REFERENCES}

AlBerts, C. C. (1989). Aspectos ecológico-componamentais de duas espécies de roedores murbideos [Ecological and behavioral aspects 
of two species of muroid rodents]. Unpublished master's thesis, Universidade de São Paulo, São Paulo, Brazil.

Barnett, S. A. (1975). The rat. Chicago: Chicago University Press

BARRY, R. E., JR., \& FrancQ, E. N. (1980). Orientation to landmarks within the preferred habitat by Peromyscus leucopus. Joumal of Mammalogy, 61, 292-303.

Birke, L. A., D'Udine, B., Albonetti, M. E. (1985). Exploratory behavior of two species of murid rodents, Acomys cahirinus and Mus musculus: A comparative study. Behavioral \& Neural Biology, 43, 143-161.

Buнот, M.-C. (1986). Nest-box exploration and choice in male and female mice tested under individual and social conditions. Behavioural Processes, 13, 119-148.

BuHOT, M.-C. (1987). Mouse exploration and choice of nestboxes differing in size. Animal Learning \& Behavior, 15, 382-394.

BuHOT, M.-C. (1989). Exploration and choice by mice among nest boxes differing in size: Influence of the inner and the outer dimensions. Quarterly Journal of Experimental Psychology, 41B, 49-64.

Buhot-Averseng, M.-C. (1981). Nestbox choice in the laboratory mouse (Mus musculus): Preferences for nest boxes differing in design (size and/or shape) and composition. Behavioural Processes, 6 , 337-384.

Charlton, S. G. (1984). Hoarding-induced lever pressing in golden hamsters (Mesocricetus auratus): Ilumination, time of day, and shock as motivating operations. Journal of Comparative Psychology, 98, 327-332.

Christian, D. P. (1980). Vegetative cover, water resources, and microdistributional patterns in a desert rodent community. Journal of Animal Ecology, 49, 807-816.

Collier, G. H. (1983). Life in a closed economy: The ecology of learning and motivation. In M. D. Zeitler \& P. Harzem (Eds.), Advances in analysis of behaviour (Vol. 3, pp. 223-274). New York: Wiley.

Collier, G. H., \& Rovee-Collier, C. K. (1980). A comparative analysis of optimal foraging behavior laboratory simulation. In A. C. Kamil \& T. Sargent (Eds.), Foraging behavior: Ecological, ethological and psychological approaches (pp. 27-46). New York: Garland Press.

Cromberg, V. U. (1988). O comportamento de escavação do hamster dourado: Observaçoes sobre sua iniciação [Digging behavior in the golden hamster: Observations on its initiation]. Unpublished master's thesis, Universidade de São Paulo, São Paulo, Brazil.

Dueser, R. D., HAlletT, J. G. (1980). Competition and habitat selection in a forest-floor small mammal fauna. Oikos, 35, 293-297.

GuerRA, R. F., ADES, C. (1982). Distância entre ninho $e$ fonte e coleta de papel no hamster [Distance between nest and resource and paper hoarding in the hamster]. Ciência e Cultura (Resumos), 34, 911.

GUERRA, R. F., ADEs, C. (1983). Variáveis ecológicas no armazenamento de papel no hamster: Efeitos, a curto e a longo prazo, da distância [Ecological variables in paper hoarding by the hamster: Shortand long-term effects of distance]. Anais do $1^{\circ}$ Encontro Paulista de Etologia, 248-249, Jaboticabal.

KIlleen, P. R., Smith, J. P., \& Hanson, S. J. (1981). Central place foraging in Rattus norvegicus. Animal Behavior, 29, 64-70.

LACHER, T. L., JR., \& ALHO, K. (1989). Microhabitat use among small mammals in the Brazilian pantanal. Journal of Mammalogy, 70, $396-401$.

LORE, R., \& FlanNelly, K. (1978). Habitat selection and burrow construction by wild Rattus norvegicus in a landfill. Journal of Comparative \& Physiological Psychology, 92, 888-896.

Nicolaidis, S., DanguiR, S., \& Mathe, P. (1978). A new approach to sleep and feeding behavior in the laboratory rat. Physiology \& Behavior, 23, 717-722.

OtTONI, E. B. (1987). Escolha do local do ninho no hamster dourado (Mesocricetus auratus Waterhouse 1839) [Nest-site selection in the golden hamster (Mesocricetus auratus Waterhouse 1839)]. Unpublished master's thesis, Universidade de São Paulo, São Paulo, Brazil.

OtTONI, E. B., \& AdEs, C. (1988). Diferenças entre os sexos em nivel de atividade e alterações de peso em hamsters numa situação experimental [Differences between sexes in activity level and weight changes in hamsters in an experimental situation]. Ciência e Cultura (Resumos), 40, 984-985.

Partridge, L. (1978). Habitat selection. In I. Krebs \& N. B. Davies (Eds.), Behavioral ecology (pp. 351-376). Oxford: Blackwell Scientific.

Poucet, B., Chapuis, N., Durup, M., \&hinus-Blanc, C. (1986). A study of exploratory behavior as an index of spatial knowledge in hamsters. Animal Learning \& Behavior, 14, 93-100.

RoparTz, P. (1962). Etude dynamique du terrier du hamster doré [Dynamic study of the golden hamster's burrow]. Terre et Vie, 4, 428-441.

ShETTLEWORTH, S. J. (1988). Foraging as operant behavior and operant behavior as foraging: What have we learned? Psychology of Learning \& Motivation, 22, 1-48.

Smith, J. P., Maybee, J. G., \& Maybee, F. M. (1979). Effects of increasing distance to food and deprivation level on food hoarding in Rattus norvegicus. Behavioral \& Neural Biology, 27, 302-318.

(Manuscript received July 24, 1990;

revision accepted for publication January 25,1991 .) 